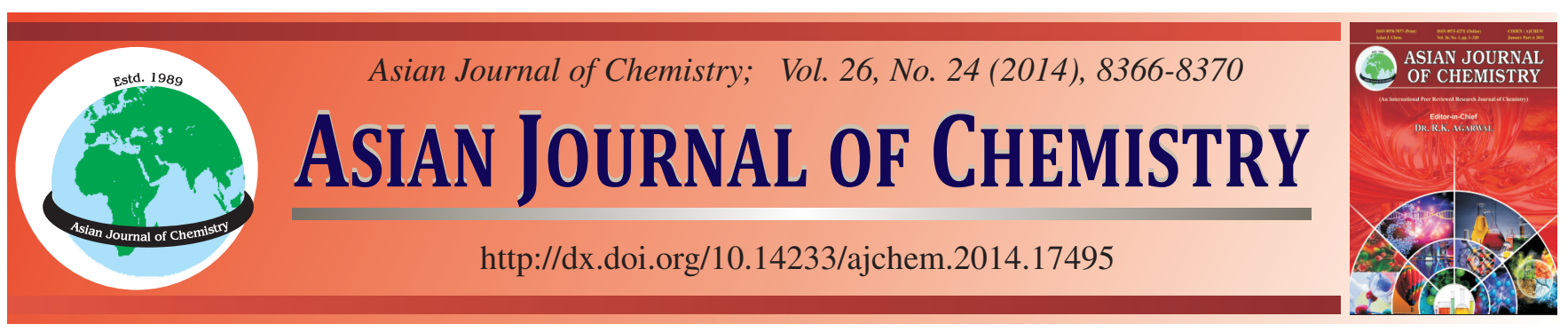

\title{
Arabinoxylan Isolated from Ispaghula Husk: A Better Alternative to Commercially Available Gelling Agents
}

\author{
Alia Erum ${ }^{1, *}$, Sajid Bashir ${ }^{1}$, Shazia Saghir ${ }^{2}$, Sadia Hina $^{1}$, Amna Batool $^{1}$ and Tahir Mahmood ${ }^{3}$
}

${ }^{1}$ Faculty of Pharmacy University of Sargodha, Sargodha, Pakistan

${ }^{2}$ Department of Chemistry, Government Jinnah Degree College for Women, Mozang, Lahore, Pakistan

${ }^{3}$ Department of Statistics, University of Sargodha, Sargodha, Pakistan

*Corresponding author: Fax: +92 48 9230507; Tel: +92 48 3220455; E-mail:alia_erum@ @otmail.com

Received: 1 March 2014;

Accepted: 12 August 2014;

Published online: 1 December 2014;

AJC-16362

Gelling behaviour of a polysaccharide arabinoxylan isolated from Ispaghula, Plantago ovata was investigated and effect of different factors such as concentration of gelling agent, temperature, $\mathrm{pH}$ and compatibility with solvents were also studied. Medicated paracetamol and acelofenac gel were formulated by using arabinoxylan as gelling agent. These gels were evaluated for rheological estimation, appearance, stability and compatibility studies and pharmacological effects. Arabinoxylan gelation was $\mathrm{pH}$ dependent, rapid gelation (less gelation time) at basic $\mathrm{pH}$ with very viscous gel, while at acidic $\mathrm{pH}$ (3) low viscosity gel was formed after $48 \mathrm{~h}$. Similarly heating facilitates gelation by reducing gelation time. Arabinoxylan gel was compatible with water, $1 \%$ propylene glycol and ethanol (30\%) while it was incompatible with 70 and $90 \%$ ethanol. Paracetamol (oral) and acelofenac (topical) gels, containing arabinoxylan as gelling agent were homogenous, stable and showed pharmacological effects comparable to gels formulated with HPMC and tragacanth as gelling agent.

Keywords: Arabinoxylan, Gelling agent, Paracetamol, Acelofenac.

\section{INTRODUCTION}

Dysphagia is major problem in general populations and more common in elderly and in children. It is the one of the leading cause for patient non compliance, sometimes resulting in serious consequences due to choking episodes. Gels and jellies as dosage form are one of the solutions of the problem as these can be easily swallowed without any discomfort to the patient preventing choking and suffocation ${ }^{1}$.

A gel is a semisolid dosage form that contains a gelling agent in order to provide stiffness to a solution or a colloidal dispersion. Gel as dosage form offers a number of advantages such as patient compliance, satisfactory bioadhesion, nonirritating and non-sensitizing effects, drug release control. That is the reason a number of natural, semi synthetic or synthetic polymers based gels are used as vehicles for different types of pharmaceutical applications from the last few decades ${ }^{2}$.

Ispaghula (Plantago ovata) is a common plant of IndoPak subcontinent. Ispaghula husk is a common remedy for chronic constipation, amoebic and bacillary dysentery, diarrhoea and a number of ailments ${ }^{3}$. It's husk and isolated mucilage have number of pharmaceutical applications. They are used as binder, thickening agent, superdisintegrant and are also used in the design of sustained release formulations ${ }^{4}$. Arabinoxylan is a polysaccharide polymer isolated from husk and seeds of ispaghula by alkali and water extraction ${ }^{5,6}$. This polysaccharide represents a significant portion of human dietary fiber intake, offering nutritional benefits as soluble and insoluble fiber. Arabinoxylans are important pharmaceutically, as they have been reported as emulsifying agent, suspending agents and binders ${ }^{7,8}$.

Arabinoxylans form highly viscous solutions and they can form gels under the action of certain oxidizing agents. This oxidative gelation was first reported by Durham ${ }^{9}$. Unlike most of polysaccharide gels, arabinoxylan gelation process and gel properties are governed by the establishment of both covalent (di-FA, tri-FA bridges) linkages and weak (hydrogen) interactions ${ }^{10,11}$. These properties depend on arabinoxylan structural, characteristics like molecular weight, arabinose to xylose ratio, as well as ferulic acid content and location ${ }^{12-14}$. Wheat and bran arabinoxylan could have potential applications for colonspecific protein delivery due to their macro-porous structure with mesh sizes varying from 200 to $400 \mathrm{~nm}^{15}$.

The present work is focused on studying the gelling ability of arabinoxylan from Ispaghula husk. Various factors effecting gelation were also studied. Medicated gels such as acelofenac and paracetamol were formulated using arabinoxylan as gelling agent. Arabinoxylan gelling properties in these formulations were compared with commercially available gelling agents. 
EXPERIMENTAL

Acute toxicity of arabinoxylan: Acute toxicity study of arabinoxylan was carried out in two animal species rabbits and mice. Acute dermal toxicity and eye irritation tests were also carried out in rabbits.

Arabinoxylan gel formation: Gel was prepared by the slight modification of method of Kumar and Kumar ${ }^{16}$. Distilled water $(100 \mathrm{~mL})$ was added in a beaker and stirred with a magnetic stirrer to create a vortex. Arabinoxylan powder was sieved gradually in portions on distilled water vortex. Stirring was stopped and clumps were broken with spatula and were again stirred for $2 \mathrm{~h}$. After stirring, solution was kept for gelation for $48 \mathrm{~h}$.

\section{Factors effecting arabinoxylan gelation}

Concentration of arabinoxylan: To evaluate the effect of concentration of gelling agent on gelation, gel was prepared by the above mentioned method by using different concentrations of arabinoxylan $0.5,1$ and $2 \%$. Viscosity of prepared gels was measured by viscometer and rheogram was constructed.

Effect of pH on arabinoxylan gel: The effect of $\mathrm{pH}$ on arabinoxylan mediated gelation was studied. Arabinoxylan ( $1 \%)$ was added in dispersing medium with different $\mathrm{pH}(2$, $4,5,6,8,12$ and 13). The $\mathrm{pH}$ was adjusted by adding $\mathrm{HCl}$ and $\mathrm{NaOH}$ solutions and time of gelation was observed.

Effect of heat on arabinoxylan gel: The effect of heat on gelling behaviour of arabinoxylan was studied. The temperature of distilled water was increased slightly after adding arabinoxylan and gelation time was noted.

Compatibility with solvents: The compatibility of arabinoxylan with solvents such as water, ethanol (30, 50 and $70 \%$ ) and propylene glycol was tested.

Susceptibility to fungal contamination: Prepared arabinoxylan gel was stored for a period of 3 months in an open container and was observed for any fungal growth.

Formulation of medicated gels: Medicated gels such as paracetamol (oral) and acelofenac (topical) were formulated by following Gohel et al. ${ }^{17}$ and Patel ${ }^{18}$ methods, using arabinoxylan as gelling agent. These gels were compared with other commercially available gelling agents (HPMC and tragacanth). Composition of paracetamol gel formulations is shown in Table-1 and acelofenac gel formulations in Table-2

\section{TABLE-1}

COMPOSITION OF PARACETAMOL GEL FORMULATIONS

\begin{tabular}{lccc} 
Ingredients $(\mathrm{g})$ & $\mathrm{F} 1$ & $\mathrm{~F} 2$ & $\mathrm{~F} 3$ \\
\hline Paracetamol & 2.5 & 2.5 & 2.5 \\
Arabinoxylan & 0.5 & 1.15 & - \\
Tragacanth & - & - & 2.5 \\
Sucrose & 66 & 66 & 66 \\
PEG & 10 & 10 & 10 \\
Citric acid & 0.05 & 0.05 & 0.05 \\
Sodium citrate & 0.3 & 0.3 & 0.3 \\
Methyl paraben & 0.02 & 0.02 & 0.02 \\
Water & 100 & 100 & 100 \\
\hline
\end{tabular}

Paracetamol oral soft gel (F1) was prepared by sieving $(0.5 \mathrm{~g})$ AX gradually in portions in $50 \mathrm{~mL}$ of distilled water maintained at $95{ }^{\circ} \mathrm{C}$. Sucrose $(66 \mathrm{~g})$ was added with stirring. Paracetamol (2.5 g) polyethylene glycol ( $10 \mathrm{~g})$ citric acid (0.05 $\mathrm{g})$ and methylparaben $(0.02 \mathrm{~g})$ were also added with stirring. Finally, sodium citrate $(0.5 \mathrm{~g})$ in distilled water was added to mixture and weight was adjusted to $100 \mathrm{~g}$ with water. F2 and F3 were prepared in the same manner except containing $(1.15 \mathrm{~g})$ arabinoxylan and (2.5 g) tragacanth as gelling agents, respectively.

TABLE-2

COMPOSITION OF ACELOFENAC GEL FORMULATIONS

\begin{tabular}{cccc}
\hline Ingredients $(\mathrm{g})$ & $\mathrm{F} 4$ & $\mathrm{~F} 5$ & $\mathrm{~F} 6$ \\
\hline Acelofenac & 1.5 & 1.5 & 1.5 \\
HPMC & 5.0 & - & - \\
Arabinoxylan & - & 0.5 & 1 \\
Propylene glycol & 10 & 10 & 10 \\
Methyl paraben & 0.18 & 0.18 & 0.18 \\
Propyl paraben & 0.02 & 0.02 & 0.02 \\
Water qs & 100 & 100 & 100 \\
\hline
\end{tabular}

Acelofenac gels (F5, F6) were prepared by using arabinoxylan (0.5 and $1 \%)$, respectively, as gelling agent. Arabinoxylan was dissolved in $40 \mathrm{~mL}$ distilled water and acelofenac was dispersed in $40 \mathrm{~mL}$ distilled water. Propylene glycol $(10 \mathrm{~g})$ and preservative methyl paraben $(0.18 \%)$ were added with constant stirring to drug solution. The drug solution was added to polymer solution in small increment with constant stirring. Distilled water was then added to adjust the gel weight to $100 \mathrm{~g}$. Acelofenac gel F4 of same composition was prepared using hydroxypropyl methyl cellulose (5\%) as gelling agent. In this case polymer solution was warmed to form gel.

Evaluation of medicated gels: The medicated gels were evaluated for rheological estimation appearance, stability studies, compatibility studies and pharmacological effects.

Compatibility studies: Compatibility of arabinoxylan with active agents (paracetamol and acelofenac) was tested by FTIR spectrophotometer analysis (IR Prestage 21, Shimadzu). The pellets were prepared in $\mathrm{KBr}$ press ( $2 \mathrm{mg}$ sample in 200 $\mathrm{mg} \mathrm{KBr}$ ) under a hydraulic pressure of $150 \mathrm{~kg} / \mathrm{cm}^{2}$.

Viscosity and pH measurement: Viscosity of gels was evaluated by Brookfield viscometer using spindle 4 at $6 \mathrm{rpm}$. The determinations were carried out in triplicate and the average of three readings was recorded. $\mathrm{pH}$ was measured by digital pH meter (3510 Jenway).

Stability studies: For stability studies, medicated gels were stored at 8,25 and $40{ }^{\circ} \mathrm{C}$ and after one month, the viscosity and $\mathrm{pH}$ of stored samples were measured.

Visual inspection: Visual inspection of the product was carried out for grittiness and stickiness by mildly rubbing the gel sample between fingers.

\section{Study of pharmacological effects of gels}

Antipyretic effect of paracetamol gel: The experimental protocols approved by the Animal ethical committee of the Faculty of Pharmacy, University of Sargodha, were followed throughout the experimentation for the care of laboratory animals. The antipyretic effects of paracetamol gel formulations were investigated on albino rabbits of both sexes, weighing between 1.5 and $1.6 \mathrm{~kg}$. The animals were kept at animal house of the Faculty of Pharmacy, University of Sargodha and fed with standard diet. Baseline temperature of rabbits was noted by rectal administration of thermometer. 
Pyrexia was induced by $1-2 \mathrm{~mL}$ of (15 \%) brewers yeast solution administration. Antipyretic effects of gel formulations (F1, F2 and F3) were determined by oral administration of gel $(35 \mathrm{mg} / \mathrm{kg}$ ) and noting the rectal temperature hourly after $3 \mathrm{~h}$ of administration of gel.

Antiinflammatory effects of acelofenac gels: Antiinflammatory effects of acelofenac gels were evaluated by carageenan-induced paw oedema in mice through method used by Kumar et al..$^{19}$ All mice were divided in 3 groups $(n=4)$ in each group. Group I served as control and received no treatment. $0.5 \mathrm{~g}$ of F6 (arabinoxylan containing acelofenac gel) was rubbed with index finger on the plantar surface of the left hind paw of group II mice and HPMC containing acelofenac gel was rubbed on the left hind paws of group III mice. After $1 \mathrm{~h}$ of treatment, $0.1 \mathrm{~mL}$ carrageenan suspension ( $1 \%$ ) freshly prepared in normal saline was injected on the plantar surface of left hind paw of mice to produce inflammation and the location of injection was marked. By using vernier caliper, the diameter of the paw was measured at 1,2 and $3 \mathrm{~h}$ intervals after the carrageenan injection at the marked location. The inflammation developed after carrageenan injection was the difference between the basal value and that measured at different time intervals noted in millimeters. The hind paw oedema inhibitions of different gel formulations were calculated by comparing with the untreated control mice by using the following equation.

Inhibition of paw oedema $(\%)=$

$$
\frac{\left(\mathrm{V}_{\mathrm{t}}-\mathrm{V}_{\mathrm{o}}\right)_{\text {control }}-\left(\mathrm{V}_{\mathrm{t}}-\mathrm{V}_{\mathrm{o}}\right)_{\text {treated }}}{\left(\mathrm{V}_{\mathrm{t}}-\mathrm{V}_{\mathrm{o}}\right)_{\text {control }}} \times 100
$$

where, $\mathrm{V}_{\mathrm{t}}$ is the rat paw volume at time $\mathrm{t}, \mathrm{V}_{\mathrm{o}}$ is the initial rat paw volume (basal value), $\left(\mathrm{V}_{\mathrm{t}}-\mathrm{V}_{\mathrm{o}}\right)$ control is the oedema produced in the control group and $\left(\mathrm{V}_{\mathrm{t}}-\mathrm{V}_{\mathrm{o}}\right)$ treated is the oedema produced in the treatment group.

\section{RESULTS AND DISCUSSION}

Toxicity testing established the good level of safety of polysaccharide as no mortality was reported in any of the treated animal. Arabinoxylan formed a white opaque gel at a minimum concentration of $0.5 \%$. From rheological investigation, its thixotropic behaviour was observed at all $(0.5,1$ and $2 \%$ ) concentrations as depicted in Fig. 1. The viscosity of gels decreased with increased shear rate.

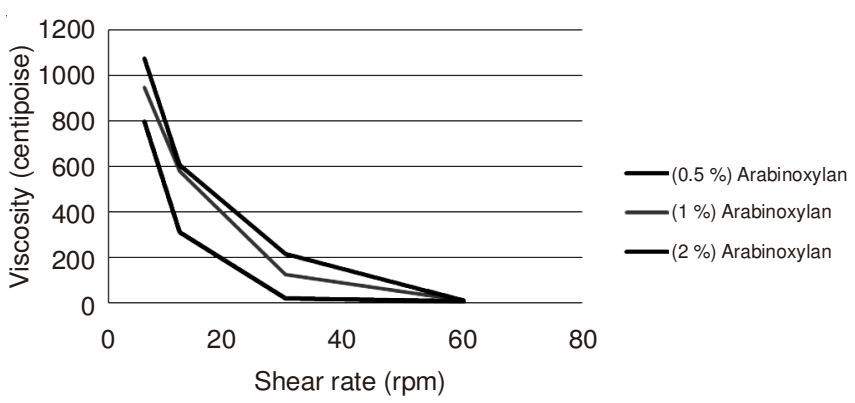

Fig. 1. Rheogram showing thixotropic behaviour of arabinoxylan gel

Some gelling agents such as carbomers form gel at basic $\mathrm{pH}$ so they require a $\mathrm{pH}$ adjusting chemical to create the gel after the gelling agent has been added in the dispersing medium ${ }^{20}$.
Effect of $\mathrm{pH}$ on arabinoxylan gelation was evaluated. Arabinoxylan showed $\mathrm{pH}$ dependent gelation. It took less gelation time at basic $\mathrm{pH} 8$ i.e. a gelation time of 2-3 h with very viscous gel. However, at $\mathrm{pH}$ 11-12, no gelation occurred while at acidic $\mathrm{pH} 3$, low viscosity gel was formed after $48 \mathrm{~h}$. Some gelling agents have better solubility in cold water (methylcellulose and poloxamers) while others in hot water such as bentonite, gelation and sodium carboxyethylcellulose. However, arabinoxylan forms gel in both cold and hot solutions but heating facilitates gelation by reducing the gelation time as shown in Table-3.

TABLE-3

EFFECT OF TEMPERATURE ON ARABINOXYLAN GELATION

\begin{tabular}{cc}
\hline Temperature $\left({ }^{\circ} \mathrm{C}\right)$ & Gelation time $(\mathrm{h})$ \\
\hline $30-40$ & $36-48$ \\
50 & $24-36$ \\
$60-70$ & within 0.5 \\
\hline
\end{tabular}

Furthermore, to justify the use of gelling agent in different pharmaceutical formulations containing various solvents the compatibility of arabinoxylan gel (2\%) was tested with various solvents such as water, propylene glycol and ethanol (Table-4). Arabinoxylan was found to be compatible with water, propylene glycol and $30 \%$ ethanol. Increased volumes of ethanol i.e. 50 and $70 \%$ showed physical incompatibility resulting in separation of ethanol from gel. Hence this finding justifies the use of arabinoxylan in aqueous formulations as well as formulations containing low concentration of ethanol.

\begin{tabular}{ccc} 
& \multicolumn{2}{c}{ TABLE-4 } \\
SOLVENT COMPATIBILITY OF ARABINOXYLAN GEL \\
\hline Solvent & Compatibility & Viscosity (cps) \\
\hline Water & Compatible & 1185 \\
$1 \%$ Propylene glycol & Compatible & 1025 \\
$30 \%$ Ethanol & Compatible & 7719 \\
$50 \%$ Ethanol & Incompatible & - \\
$70 \%$ Ethanol & Incompatible & - \\
\hline
\end{tabular}

Susceptibility of gel to fungal contamination was also noted. No fungal growth was observed in gel after 3 months of storage in open container Fig. 2.
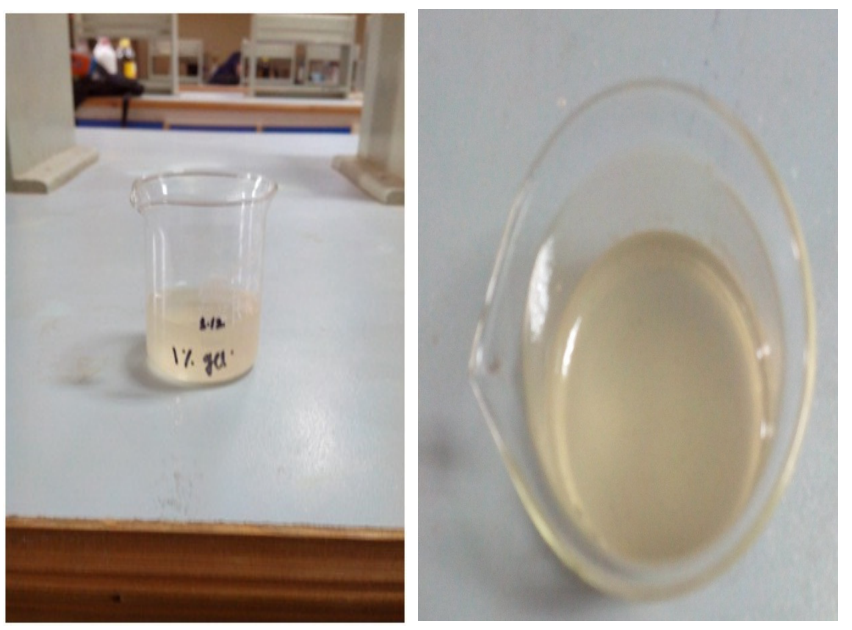

Fig. 2. $1 \%$ Arabinoxylan gel after three month storage 
Paracetamol soft gels (F1 and F2) were formulated with varying concentration of $\mathrm{AX}(0.5$ and $1.15 \%)$ while F3 contained tragacanth $(2.5 \%)$ as gelling agent. Arabinoxylan was compatible with paracetamol as shown by FTIR spectrum in Fig. 3. Physical mixture of arabinoxylan and paracetamol represented by b, have peaks at $3163.26 \mathrm{~cm}^{-1}$ due to $\mathrm{O}-\mathrm{H}$ stretching, $2588.4 \mathrm{~cm}^{-1}$ due to $\mathrm{C}-\mathrm{H}$ stretching, $1238.30 \mathrm{~cm}^{-1}$ due to $\mathrm{C}-\mathrm{N}-\mathrm{H}$ group of paracetamol in mixture. Peaks at $3496 \mathrm{~cm}^{-1}$ due to $\mathrm{OH}$ stretching and at $1159 \mathrm{~cm}^{-1}$ were due to presence of arabinosyl side chains of arabinoxylan. No additional peaks and no shift in bands were observed.

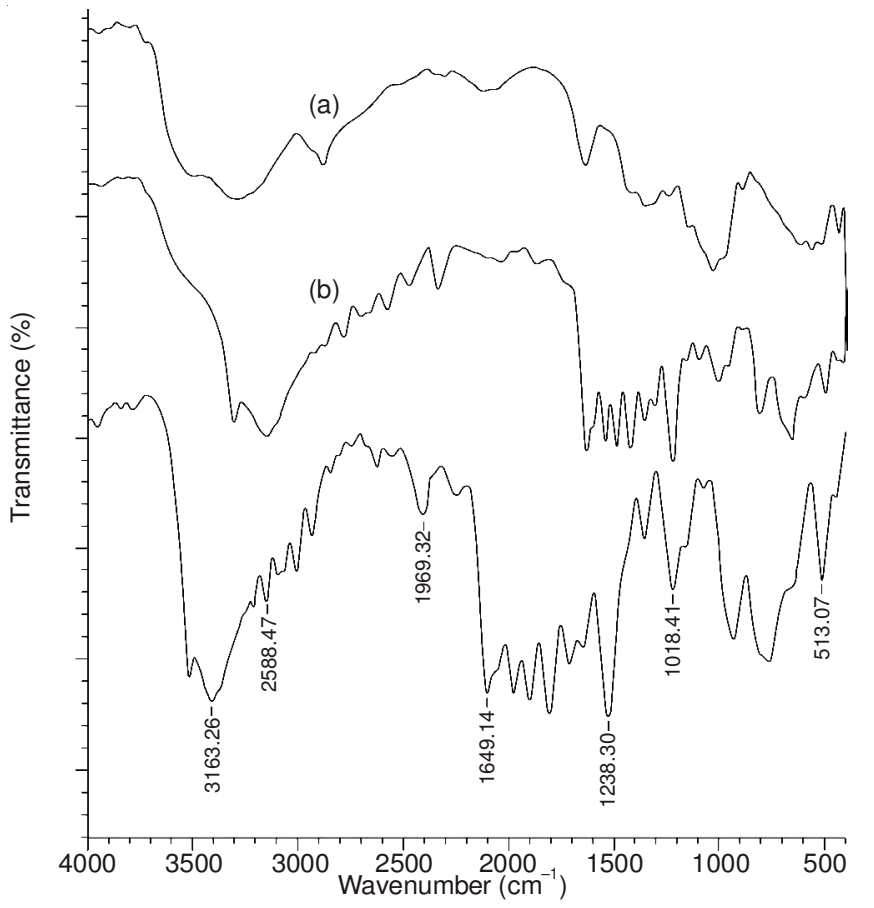

Fig. 3. FTIR spectra of (a) Arabinoxylan (b) physical mixture of paracetamol and arabinoxylan (1:1) (c) paracetamol

Arabinoxylan containing gel formulations (F1 and F2) were opaque, homogenous and even at low concentration $(1.15 \%)$ produced viscous gel comparable to F3 containing $2.5 \%$ tragacanth as shown in Table-5. The $\mathrm{pH}$ of soft paracetamol gels were between 6.13 (gel containing tragacanth) and 6.63 (gel containing arabinoxylan) which are considered appropriate as paracetamol is stable ${ }^{21}$ between $\mathrm{pH}$ 5-7.
TABLE-5

EVALUATION PARAMETERS OF PARACETAMOL SOFT GEL FORMULATIONS

\begin{tabular}{ccccc}
\hline Formulation & $\mathrm{pH}$ & Homogeneity & $\begin{array}{c}\text { Viscosity } \\
\text { cps }\end{array}$ & $\begin{array}{c}\text { Physical } \\
\text { appearance }\end{array}$ \\
\hline F1 & $6.63 \pm 0.04$ & Homogenous & $898 \pm 22$ & Opaque \\
F2 & $6.60 \pm 0.06$ & Homogenous & $1125 \pm 42$ & Opaque \\
F3 & $6.13 \pm 0.03$ & Homogenous & $1132 \pm 36$ & Opaque \\
\hline
\end{tabular}

Antipyretic effects of gels F1 and F2 were comparable to F3 as shown in Table-6.

FT- IR spectroscopic analysis confirmed the compatibility between arabinoxylan and acelofenac as shown in Fig. 4. Physical mixture of arabinoxylan and acelofenac represented by $\mathrm{b}$, have peaks at $1,720.50 \mathrm{~cm}^{-1}(-\mathrm{C}=\mathrm{O}$ stretching $)$ at 1288.45 due to $\mathrm{C}-\mathrm{O}$ stretching and at $1720.50 \mathrm{~cm}^{-1}$ due to $-\mathrm{C}=\mathrm{C}$ stretching of aromatic group in acelofenac. Peaks at $3496 \mathrm{~cm}^{-1}$ due to $\mathrm{OH}$ stretching and at $1159 \mathrm{~cm}^{-1}$ were due to presence of arabinosyl side chains of arabinoxylan. No additional peaks and no shift in bands were observed.

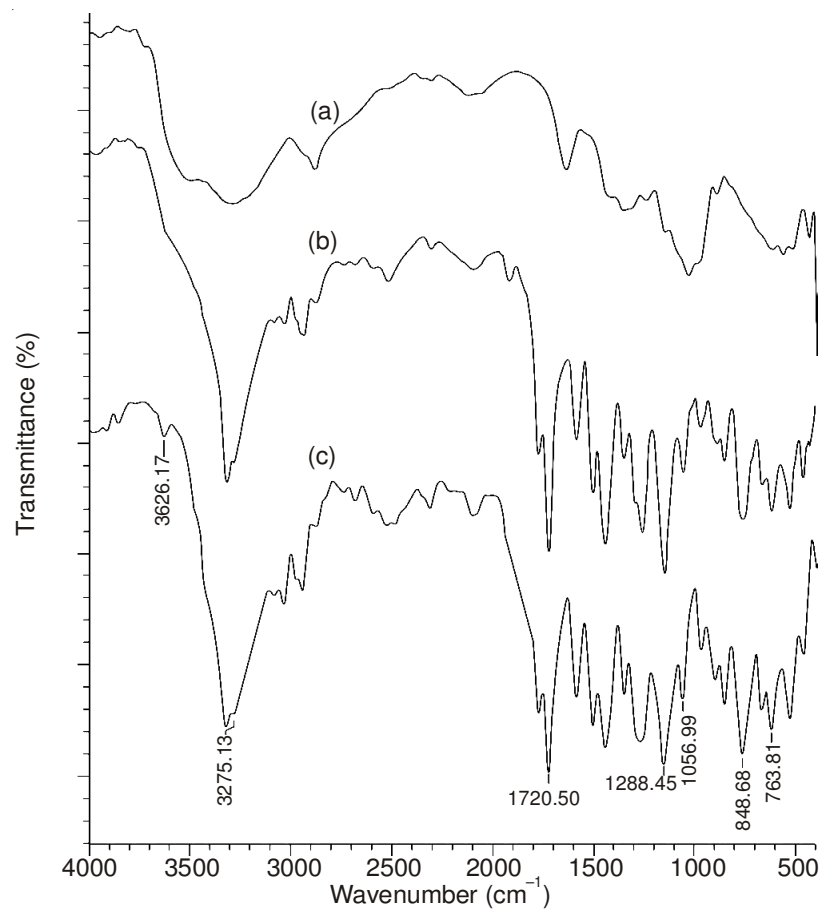

Fig. 4. FTIR spectra (a) arabinoxylan (b) arabinoxylan and acelofenac (c) acelofenac

\begin{tabular}{|c|c|c|c|c|c|c|}
\hline \multirow{4}{*}{ Treatment } & \multicolumn{5}{|c|}{$\begin{array}{l}\text { TABLE-6 } \\
\text { FFECT OF PARACETAMOL } \\
\text { OUCED PYREXIA IN RABBITS }\end{array}$} & \\
\hline & \multicolumn{6}{|c|}{ Rectal temperature $\left({ }^{\circ} \mathrm{C}\right)$} \\
\hline & \multicolumn{2}{|c|}{ After yeast injection } & \multicolumn{4}{|c|}{ After drug administration } \\
\hline & $0 \mathrm{~h}$ & $24 \mathrm{~h}$ & $1 \mathrm{~h}$ & $2 \mathrm{~h}$ & $3 \mathrm{~h}$ & $4 \mathrm{~h}$ \\
\hline Control & $38 \pm 0.01$ & $40.5 \pm 0.02$ & $\begin{array}{c}40.2 \pm 0.01 \\
(12 \%)\end{array}$ & $\begin{array}{c}40 \pm 0.03 \\
(20 \%)\end{array}$ & $\begin{array}{c}40 \pm 0.02 \\
(20 \%)\end{array}$ & $\begin{array}{c}40 \pm 0.01 \\
(20 \%)\end{array}$ \\
\hline $\mathrm{F} 1$ & $38.4 \pm 0.03$ & $40.4 \pm 0.05$ & $\begin{array}{c}39.2 \pm 0.02 \\
(60 \%)\end{array}$ & $\begin{array}{c}38.8 \pm 0.02 \\
(80.5 \%)\end{array}$ & $\begin{array}{c}38.4 \pm 0.04 \\
(100 \%)\end{array}$ & $\begin{array}{c}38.4 \pm 0.02 \\
(100 \%)\end{array}$ \\
\hline $\mathrm{F} 2$ & $38.9 \pm 0.05$ & $40.4 \pm 0.02$ & $\begin{array}{c}39.3 \pm 0.01 \\
(73.33 \%)\end{array}$ & $\begin{array}{l}39 \pm 0.02 \\
(93.33 \%)\end{array}$ & $\begin{array}{c}38.9 \pm 0.03 \\
(100 \%)\end{array}$ & $\begin{array}{c}38.9 \pm 0.03 \\
(100 \%)\end{array}$ \\
\hline $\mathrm{F} 3$ & $38.3 \pm 0.01$ & $40 \pm 0.02$ & $\begin{array}{c}38.8 \pm 0.02 \\
(70.5 \%)\end{array}$ & $\begin{array}{c}38.4 \pm 0.01 \\
(94 \%)\end{array}$ & $\begin{array}{c}38.3 \pm 0.03 \\
(100 \%)\end{array}$ & $\begin{array}{c}38.3 \pm 0.02 \\
(100 \%)\end{array}$ \\
\hline
\end{tabular}




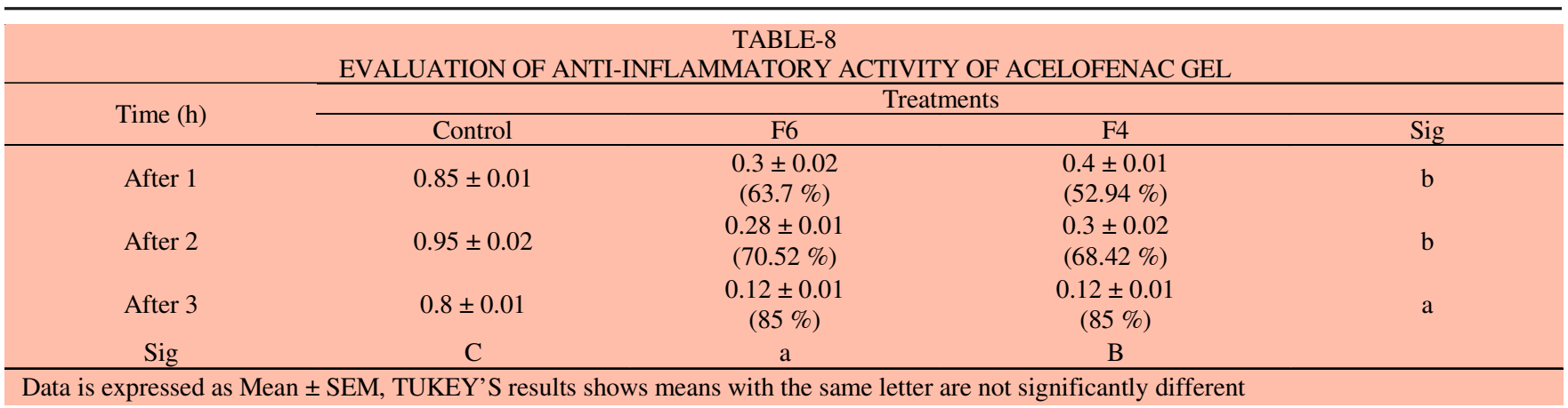

Acelofenac topical gel formulated with arabinoxylan (F5, F6) was homogenous with $\mathrm{pH}$ range of 6.76-6.69 and didn't cause any skin irritation as shown in Table-7.

\begin{tabular}{ccccc}
\multicolumn{5}{c}{ TABLE-7 } \\
\multicolumn{5}{c}{$\begin{array}{c}\text { EVALUATION PARAMETERS OF } \\
\text { ACELOFENAC GEL FORMULATIONS }\end{array}$} \\
\hline Formulation & $\mathrm{pH}$ & Homogeneity & $\begin{array}{c}\text { Viscosity } \\
(\mathrm{cps})\end{array}$ & $\begin{array}{c}\text { Skin } \\
\text { irritation }\end{array}$ \\
\hline F4 & $6.53 \pm 0.05$ & Homogenous & $1347 \pm 55$ & Nil \\
F5 & $6.76 \pm 0.03$ & Homogenous & $1155 \pm 45$ & Nil \\
F6 & $6.69 \pm 0.05$ & Homogenous & $1456 \pm 67$ & Nil \\
\hline
\end{tabular}

Acelofenac gel F6 containing arabinoxylan as gelling agent caused significant inhibition of paw oedema as shown in Table-8 $(63.7 \%)$ even after $1 \mathrm{~h}$ while the gel containing HPMC caused slight inhibition (52.94\%) after $1 \mathrm{~h}$ and $68.42 \%$ after $2 \mathrm{~h}$ of application. After $3 \mathrm{~h}$, both formulations showed equivalent inhibition $(85 \%)$. Hence, the results indicate that arabinoxylan is a better alternative to HPMC in acelofenac gel.

\section{REFERENCES}

1. D.A. Satyanarayana, P.K. Kulkarni and H.G. Shivakumar, Curr. Drug Ther., 6, 79 (2011)

2. C. Tas, Y. Özkan, A. Savaser and T. Baykara, Farmaco, 58, 605 (2003).

3. S.M. Shamim, Pak. J. Pharmacol., 21, 49 (2004).
4. S. Shanmugam, R. Manavalan, D. Vankappayya, K. Sundramoorthy, V.M. Mounnissamay, S. Hemalatha and T. Ayyappan, Nat. Prod. Radiance, 4, 478 (2005)

5. S. Saghir, M.S. Iqbal, M.A. Hussain, A. Koschella and T. Heinze, Carbohydr. Polym., 74, 309 (2008).

6. M.S. Iqbal, J. Akbar, M.A. Hussain, S. Saghir and M. Sher, Carbohydr. Polym., 83, 1218 (2011).

7. M.P. Yadav, D.B. Johnston, A.T. Hotchkiss Jr. and K.B. Hicks, Food Hydrocoll., 21, 1022 (2007).

8. M.R.P. Rao, Int. J. Pharm. Tech. Res., 3, 1191 (2011).

9. R.K. Durham, Cereal Chem., 2, 297 (1925).

10. E. Vansteenkiste, C. Babot, X. Rouau and V. Micard, Food Hydrocoll., 18, 557 (2004).

11. E. Carvajalmillan, S. Guilbert, M. Morel and V. Micard, Carbohydr. Polym., 60, 431 (2005).

12. M.S. Izydorczyk and C.G. Biliaderis, Carbohydr. Polym., 28, 33 (1995).

13. O. Rattan, M.S. Izydorczyk and C.G. Biliaderis, LebenWiss Tech., 27, 550 (1994)

14. G. Dervilly-Pinel, L. Rimsten, L. Saulnier, R. Andersson and P. Åman, Cereal Sci., 34, 207 (2001).

15. E. Carvajal-Millan, V. Landillon, M.-H. Morel, X. Rouau, J.-L. Doublier and V. Micard, Biomacromolecules, 6, 309 (2005).

16. V. Kumar and S. Kumar, Int. J. Pharm. Pharm. Sci., 3, 55 (2011).

17. M.C. Gohel, R.K. Parikh, S.A. Nagori, S.N. Shah and M.R. Dabhi, Indian J. Pharm. Sci., 71, 120 (2009).

18. J. Patel, J. Pharm. Sci., 1, 160 (2011).

19. R. Kumar, M.B. Patil, S.R. Patil and M.S. Paschapur, Int. J. Pharm. Tech. Res., 1, 695 (2009).

20. A. Hellerbach, V. Schuster, A. Jansen and J. Sommer, PLoS ONE, 8, e70343 (2013).

21. A.P. Pawar, A.R. Paradkar, S.S. Kadam and K.R. Mahadik, AAPS Pharm. Sci. Tech., 5, 57 (2004). 